\title{
Profile Interview: Dr Lucinda Manda-Taylor
}

\author{
"A good leader should be passionate because leadership is not simply about having a position"
}

\section{Thengo Kavinya talks to Lucinda
the $M M J$ professional experience.}

LMT: I am an applied ethicist by training and profession. I was educated in Malawi and South Africa. I did my university education at the former University of Natal, Pietermaritzburg Campus and graduated with a $\mathrm{PhD}$ in applied ethics from the University of KwaZuluNatal after it had merged with the University of DurbanWestville. I joined the College of Medicine in 2009 as a parttime lecturer, and in March 2010 I was offered a six-month contract as a compliance officer for the College of Medicine Research and Ethics Committee (COMREC). In August 2010, I was offered the position of the Institutional Review Board (IRB) Administrator for COMREC after the College management had approved supporting the full-time posts of compliance officer and IRB Administrator. I currently manage and oversee the day-to-day operations of the ethics committee. I am also an honorary senior lecturer in the Department of Health Systems and Policy, within the School of Public Health and Family Medicine. I teach bioethics to students on the Mahatma Gandhi campus.

From the foregoing, I believe that my education and professional experience provides me with the requisite expertise, training, motivation, and leadership skills to take on any new challenge, including my new role as editor-inchief of the Malawi Medical Journal (MMJ).

\section{TK: How do you plan on taking up the challenge of this new role?}

LMT: To begin with, let me state that the MMJ has achieved so much over the years and each individual editor has left an indelible mark. A testament to the great work is the journal's improved impact factor of 0.837 - the highest ever.

This achievement provides me with a challenge to continue to grow the journal's impact factor, and my goal during my tenure is to improve it to 1.0. That will require that we engage with the College of Medicine researchers as well as our colleagues in our affiliate institutions to publish important findings in the MMJ. Having local researchers publish their research findings with the College's medical journal will increase our citation records thereby increasing our impact.

Another perennial challenge concerns the availability of funds to support the functions and operations of the $M M J$. In his farewell editorial, Dr Chiwoza Bandawe points out that the rising costs of printing have severely constrained the $M M J$ 's objective, which is to "'stimulate dialogue amongst researchers and health professionals in Malawi through information that will aid daily practice, lifelong learning, and career development.' Hard copies are essential in district hospitals and rural health centres, where Internet access is a challenge. We are trying to revive print copies in addition to our online edition so that the reach of the $M M J$ is far wider." Part of my mandate and goal will be to revive the quarterly print issues by slowly reintroducing income-generating mechanisms that will enable us to be somewhat self-sufficient

http://dx.doi.org/10.4314/mmj.v28i3.1 and self-sustaining. For example, we plan to introduce an author-pay model, resuscitate our subscription system, and vigorously pursue advertisers to buy advertorial space. Such revenue will enable the $M M J$ to print our quarterly issues, thereby extending our reach.

\section{TK: What would you say are the strengths that you've brought to the $M M J$ ?}

LMT: I am a passionate individual who enjoys taking on new challenges. Being passionate is a great character trait, because it is a quality that is inspires those that you work with to remain committed, motivated, and involved. A good leader should be passionate, because leadership is not simply about having a position; it is about problem-solving and influencing others through inspiration to achieve desired outcomes.

TK: What are your views on the current standards of scientific research publications in the country and what do you think should change or improve?

LMT: The current standards of our scientific publications for the $M M J$ are good. Again, the improvement in our impact factor pays great testimony to the quality of work that is being published from Malawi and elsewhere on the continent. However, I need to mention here that part of our success story lies not only in the important work our editorial board members play, or the critical role that independent reviewers play in the peer review process, but to our very committed intern (now deputy editor), Dr Andrew Mataya, who for years has worked tirelessly to manage the online submission and review process through ScholarOne Manuscripts, and ensure that appropriate and timely communication between the authors and the journal remained a priority. I also cannot forget the role that the desk editor, Mr Thengo Kavinya, has played in ensuring that the articles are formatted appropriately and uploaded onto the website in our online issue, as well as indexing and archiving articles in African Journals Online and PubMed, so that our visibility can increase.

Because we are an open access journal that does not request authors to pay a publication fee before the accepted article is published, this does mean that we often have an abundance of "journal shoppers" looking for free places to submit their manuscripts. Said authors do not always take into consideration the relevance and significance of the content with respect to the local audience, which we intend to stimulate. Introducing such an author-pay model, I believe, will serve to restrict and limit the "chancers", yet still enable us to maintain our standard.

TK: Describe your greatest achievement-one that you are most proud of in your life?

LMT: My two children! Being a mother is an awesome gift, and I thank God every day for this opportunity to be a parent. There are, of course, challenges that come with being a working mother. However, I make it a point to block out my weekends and reserve them for family time and activities. I believe my family also deserves the same level of passion and enthusiasm. 
TK: What are your current research interests?

LMT: I dabble in some research and my specific areas of interest are bioethics, research ethics, and community systems strengthening research. In my research work I employ my qualitative research skills to explore factors that determine or impede access to health care services, factors that motivate people to participate in research, and policy implications between health and social domains of life.

\section{TK: Any last words?}

It is my hope that in my time as the editor-in-chief of the MMJ I will carry on the great work that my predecessors began, by first maintaining an international presence for the journal, and second, improving its impact factor. 